\title{
Cryptoendolithic Antarctic Black Fungus Cryomyces antarcticus Irradiated with Accelerated Helium Ions: Survival and Metabolic Activity, DNA and Ultrastructural Damage
}

\author{
Claudia Pacelli', Laura Selbmann ${ }^{1 *}$, Ralf Moeller ${ }^{2}$, Laura Zucconi ${ }^{1}$, Akira Fujimori ${ }^{3}$ and \\ Silvano Onofri ${ }^{1}$
}

${ }^{1}$ Department of Ecological and Biological Sciences, University of Tuscia, Viterbo, Italy, ${ }^{2}$ German Aerospace Center, Institute of Aerospace Medicine, Radiation Biology Department, Space Microbiology Research Group, Cologne, Germany, ${ }^{3}$ National Institute of Radiological Sciences, Research Center for Charged Particle Therapy, Chiba, Japan

OPEN ACCESS

Edited by: Andreas Teske, University of North Carolina at Chapel Hill, United States

Reviewed by:

Issay Narumi,

Toyo University, Japan

Isao Yumoto,

National Institute of Advanced Industrial Science and Technology,

Japan

*Correspondence:

Laura Selbmann selbmann@unitus.it

Specialty section:

This article was submitted to Extreme Microbiology,

a section of the journal

Frontiers in Microbiology

Received: 29 June 2017 Accepted: 28 September 2017 Published: 17 October 2017

Citation: Pacelli C, Selbmann L, Moeller R, Zucconi L, Fujimori A and Onofri S (2017) Cryptoendolithic Antarctic Black Fungus Cryomyces antarcticus Irradiated with Accelerated Helium Ions: Survival and Metabolic Activity, DNA and Ultrastructural Damage.

Front. Microbiol. 8:2002. doi: 10.3389/fmicb.2017.02002
Space represents an extremely harmful environment for life and survival of terrestrial organisms. In the last decades, a considerable deal of attention was paid to characterize the effects of spaceflight relevant radiation on various model organisms. The aim of this study was to test the survival capacity of the cryptoendolithic black fungus Cryomyces antarcticus CCFEE 515 to space relevant radiation, to outline its endurance to space conditions. In the frame of an international radiation campaign, dried fungal colonies were irradiated with accelerated Helium ion (150 MeV/n, LET $2.2 \mathrm{keV} / \mu \mathrm{m}$ ), up to a final dose of 1,000 Gy, as one of the space-relevant ionizing radiation. Results showed that the fungus maintained high survival and metabolic activity with no detectable DNA and ultrastructural damage, even after the highest dose irradiation. These data give clues on the resistance of life toward space ionizing radiation in general and on the resistance and responses of eukaryotic cells in particular.

Keywords: cosmic rays, extremophiles, extremotolerance, fungi, $\mathrm{HZE}$ particles, $\mathrm{He}^{2+}$ ions, space radiation environment

\section{INTRODUCTION}

In looking for life on other planets, a robust and detailed understanding of the limits of radiation resistance of Earth extremophiles is extremely important. Indeed, beyond the shielding influence of Earth's magnetic field and atmosphere, strong ionizing radiations pervade the space environment, representing the major hazard for microbial survival, persistence of detectable biosignatures, and operation of spacecraft equipment (Dartnell, 2011). GCR, SEP, and trapped energetic particles in a planetary magnetic field are natural sources of radiation in space. Although only $1 \%$ of GCRs is composed by particles of high (H) charge (Z) and high energy (E) (HZE), i.e., He and Fe ions, the

Abbreviations: CFU, colony-forming units; GCR, galactic cosmic radiation; HIMAC, Heavy Ion Medical Accelerator in Chiba; HZE, high atomic charge and energy; LET, linear energy transfer; MEA, malt extract agar; NIRS, National Institute of Radiological Sciences; PCR, polymerase chain reaction; PMA-qPCR, Propidium MonoAzide-quantitative polymerase chain reaction; RAPD, random amplified polymorphic DNA; SPE, solar energetic particle events; TEM, transmission electron microscopy; XTT, colorimetric assay of cellular viability with 2,3-bis(2-methoxy-4-nitro-5-sulfophenyl)-5- [(phenylamino) carbonyl]-2H-tetrazolium hydroxide. 
HZE particles are considered one of the major damage for microorganisms accidentally traveling in space (Durante and Cucinotta, 2011). Being high-LET (linear energy transfer) radiation, they cause densely packed lesions characterized by locally multiplied damaged types and sites, which are known to be the major causes of the lethal and mutagenic effects of ionizing radiation (Goodhead, 1994, 1999; Sutherland et al., 2000). The real effect of HZE on microorganisms is still unknown since during the previous space exposure experiments microorganisms were exposed and survived to non-ionizing parameters only (Rabbow et al., 2012, 2015).

In that contest, the STARLIFE-irradiation campaign (2013-2015) aimed to study the responses of astrobiological model microorganisms to increased doses of ionizing radiation and heavy ions, mimicking representatives of the GCR, never tested before. The dose rates used in the experiments were higher than those of natural GCR (Moeller et al., 2017).

Our model organism was the Antarctic cryptoendolithic black fungus Cryomyces antarcticus CCFEE 515, previously selected for astrobiological experiments for assessing the habitability of Mars, the likelihood of Lithopanspermia, i.e., the possible transfer of life via meteorites (Mileikowsky et al., 2000; Clark, 2001; Nicholson, 2009), and for the astronauts and planetary space protection (Hawrylewicz et al., 1962; Rummel, 2001; Nicholson et al., 2009; Horneck et al., 2010). In a space experiment the fungus has already survived 18 months real space exposition and Martian simulated conditions (Onofri et al., 2012, 2015).

Cryomyces antarcticus was isolated from the McMurdo Dry Valleys in Antarctica, considered as Mars analog due to cold temperatures, dryness and high UV irradiation (Selbmann et al., 2005; Onofri et al., 2012).

In the frame of STARLIFE experiments $C$. antarcticus has already shown a high resistance to gamma radiation up to $55.61 \mathrm{kGy}\left(\mathrm{Co}^{60}\right)$ in dried condition (Pacelli et al., 2017b).

In a separate experiment the fungus has also demonstrated to tolerate densely (deuterons, ${ }^{2} \mathrm{H}$ up 1,500 Gy) and sparsely (X-rays up to $300 \mathrm{~Gy}$ ) ionizing radiation in physiological condition (Pacelli et al., 2017a). In this experiment C. antarcticus has been tested, with other astrobiological models, with accelerated Helium (150 MeV/nucleon) up to $1 \mathrm{kGy}$, as part of space-relevant ionizing radiations tested in the STARLIFE irradiation campaign (Moeller et al., 2017). Alpha particles are able to originate a high LET and a consequent higher direct biological effect (Cordero, 2017). The fungal response, after exposure in dried condition, was assessed by (i) cultivation test (CFU number), (ii) membrane damage assessment (PMA-qPCR), (iii) metabolic activity (XTT assay), (iv) DNA integrity (single gene PCRs and fingerprinting analysis), and (v) ultrastructural damage (TEM analysis).

\section{MATERIALS AND METHODS}

\section{Samples Preparation and Exposure Conditions}

Cryomyces antarcticus CCFEE 515, an Antarctic cryptoendolithic black yeast-like micro-colonial fungus, was isolated from sandstone rock collected at Linnaeus Terrace (McMurdo Dry Valleys, Southern Victoria Land) by S. Onofri during the Antarctic expedition 1980-81. Samples were prepared as follows: cell suspensions (1,000 CFU) were spread on Petri dishes of MEA medium (malt extract, powdered $30 \mathrm{~g} / \mathrm{L}$; peptone $5 \mathrm{~g} / \mathrm{L}$; agar $15 \mathrm{~g} / \mathrm{L}$; Applichem, $\mathrm{GmbH})$. Fungal colonies were incubated at $15^{\circ} \mathrm{C}$ for 3 months and dried under laminar flow in a sterile cabinet. Colonies were irradiated with accelerated helium ion (150 MeV/n, LET $2.2 \mathrm{keV} / \mu \mathrm{m}$ ) doses (ranging from 50 to $1,000 \mathrm{~Gy}$ ), at the HIMAC facility at the NIRS in Japan: the doses were 50, 100, 500, and 1,000 Gy. Controls (0 Gy) were kept in the lab at room temperature.

Dose rates used in this study were far beyond those that reach Mars' surface and objects in outer space to simulate doses that organisms would receive over extended periods of time (Moeller et al., 2017; Verseux et al., 2017). All tests were performed in triplicate.

\section{Survival Assessment Cultivation Test}

Microorganism survival was determined by measuring colony forming ability as percentages of CFU. Three of the treated colonies were re-hydrated for $72 \mathrm{~h}$ in $1 \mathrm{~mL}$ of physiological solution $(\mathrm{NaCl} 0.9 \%) ; 0.1 \mathrm{~mL}(1,000$ cells/mL) of the suspension was spread on Petri dishes supplemented with MEA (five replicates). Dishes were incubated at $15^{\circ} \mathrm{C}$ for 3 months and developing colonies were counted. Means and standard deviations were calculated. Statistical analyses were performed by one-way analysis of variance (ANOVA) and pair wise multiple comparison procedure (Tukey test, Box et al., 1978), carried out using the statistical software SigmaStat 2.0 (Jandel, United States).

\section{Membrane Damage Assessment}

Quantitative PCR after treatment with PMA was performed to assess the membrane integrity for the all irradiation doses.

After 3 days of re-hydration, PMA (Biotium, Hayward, CA, United States) at a final concentration of $200 \mu \mathrm{M}$ was added to colonies for $1 \mathrm{~h}$. PMA penetrates only damaged membrane cells, crosslinks to DNA after light exposure and thereby prevents PCR. DNA extraction, purification and quantitative PCR, used to quantify the number of fungal Internal Transcribed Spacer (ITS) ribosomal DNA fragments present in both PMA treated and non-treated samples, were performed according to Onofri et al. (2012). Before qPCR, DNAs were quantified and normalized at same concentration (2 $\mathrm{ng} / \mathrm{mL}$ ) using Qubit dsDNA HS Assay Kit (Life Technologies, United States). All tests were performed in triplicate.

\section{Determination of Metabolic Activity by XTT Assay}

Colorimetric assay of cellular viability, namely XTT assay, was performed according to the protocol in Kuhn et al. (2003). The XTT is converted to a colored formazan in the presence of cell metabolic activity. After irradiation, colonies of C. antarcticus were re-hydrated in $1 \mathrm{~mL}$ of Malt Extract (30 gr/L). After 10 days, fungal cells were washed, suspended in phosphatebuffered saline (PBS) and placed into 96 well plates, three wells for each condition. The XTT assay was performed adding 
$54 \mu \mathrm{L}$ XTT $(10 \mathrm{mg} / \mathrm{ml}) /$ menadione $(2 \mathrm{mM})$ to each well. Plates were covered with foil and incubated, in agitation, at room temperature $\left(24^{\circ} \mathrm{C}\right)$. Formazan product in the supernatant was detected by measuring the optical density at $492 \mathrm{~nm}$ (Labsystem Multiskan, Franklin, MA, United States) after 2, 3, 4, and 12 h of incubation.

\section{DNA Integrity Assessment \\ DNA Extraction, Single Gene PCR Reactions, and RAPD Analysis}

DNA was extracted from colonies using Nucleospin Plant kit (Macherey-Nagel, Düren, Germany) following the protocol optimized for fungi (Selbmann et al., 2014).

Internal Transcribed Spacer and Small Subunit region (SSU) were amplified using BioMix (BioLine $\mathrm{GmbH}$, Luckenwalde, Germany) adding $5 \mathrm{pmol}$ of each primer and 2 ng of template DNA at final volume of $25 \mu \mathrm{L}$. The amplification was carried out using MyCycler Thermal Cycler (Bio-Rad Laboratories GmbH, Munich, Germany) equipped with a heated lid. The fungal rDNA regions were amplified using ITS4, ITS5, LR5, and LR7 and amplification conditions are as reported in Selbmann et al. (2011). Band intensities were measured and compared by using Image J software (Schneider et al., 2012). The whole genome was analyzed through fingerprinting analysis (Random Amplified Polymorphic DNA, RAPD protocol) and was performed using $\mathrm{GGA}_{7}$ primer according to Selbmann et al. (2011).

Primers specification as follows: ITS4 (TCCTCCGCTTA TTGATATGC, White et al., 1990); ITS5 (GGAAGTAAAAGT CGTAACAAGG, White et al., 1990); LR5 (TCCTGAGGGA AACTTCG, Vilgalys and Hester, 1990); LR7 (TACTACCACC AAGATCT, Vilgalys and Hester, 1990); (GGA) 7 (GGA GGA GGA GGA GGA GGA GGA, Kong et al., 2000).

\section{Ultrastructural Damage Assessment}

After re-hydration, controls and colonies irradiated with medium and maximum irradiation dose (500 and 1,000 Gy) were prepared for TEM.

Colonies were treated with $5 \%$ glutaraldehyde/cacodylate sucrose buffer $0.1 \mathrm{M}(\mathrm{pH} 7.2)$ for $12 \mathrm{~h}$ at $4^{\circ} \mathrm{C}$, washed three times in the same buffer for $1 \mathrm{~h}$ each at $4^{\circ} \mathrm{C}$ and fixed with $1 \% \mathrm{OsO}_{4}$ $+0.15 \%$ ruthenium red in $0.1 \mathrm{M}$ cacodylate buffer $(\mathrm{pH} 7.2)$ for $3 \mathrm{~h}$ at $4^{\circ} \mathrm{C}$. Samples were washed in distilled water (two times for $30 \mathrm{~min}$ at $4^{\circ} \mathrm{C}$ ), treated with $1 \%$ uranyl acetate in distilled water for $1 \mathrm{~h}$ at $4^{\circ} \mathrm{C}$ and washed in distilled water (two times, $30 \mathrm{~min}$ at $\left.4^{\circ} \mathrm{C}\right)$. Samples were then dehydrated in ethanol solutions: 30 , $50,70 \%$ (15 min each, at room temperature) and 100\% ethanol ( $1 \mathrm{~h}$ at room temperature); then, they were infiltrated in mixtures of ethanol 100\%: LR White resin (Agar Scientific) (2:1 for $3 \mathrm{~h}$; 1:1 for $3 \mathrm{~h}, 1: 2$ overnight), in rotator, at $4^{\circ} \mathrm{C}$. The final step of the infiltration process was performed in pure resin for $36 \mathrm{~h}$. Samples were then embedded in pure resin in gelatine capsules at $48-52^{\circ} \mathrm{C}$ for 2 days and blocks were cut by a Reichert-Jung $\mathrm{E}$ Ultracut ultramicrotome equipped with diamond knife. Ultrathin sections (60-80 nm) were collected on copper grids and stained with uranyl acetate and lead citrate; then they were observed with JEOL 1200 EX II Transmission Electron Microscope. The images have been acquired using a Veleta CCD camera (Olympus Soft Imaging Solutions).

\section{RESULTS}

\section{Survival Assessment Cultivation Test}

Survival was not affected after irradiation at 50 Gy (Figure 1). From 100 Gy onward, a progressive increase of mortality was recorded with the increasing of irradiation doses; yet, C. antarcticus retained the colony-forming ability after all treatments and $65 \%$ of vitality with the respect to the laboratory control was still maintained at the highest dose applied (1,000 Gy).

\section{Metabolic Activity}

The XTT results demonstrated a decrease in C. antarcticus metabolic activity, with the increasing of helium ions irradiation doses (Figure 2). This substance is cleaved to formazan by the succinate dehydrogenase system of the mitochondrial respiratory chain. Only living cells, possessing an intact

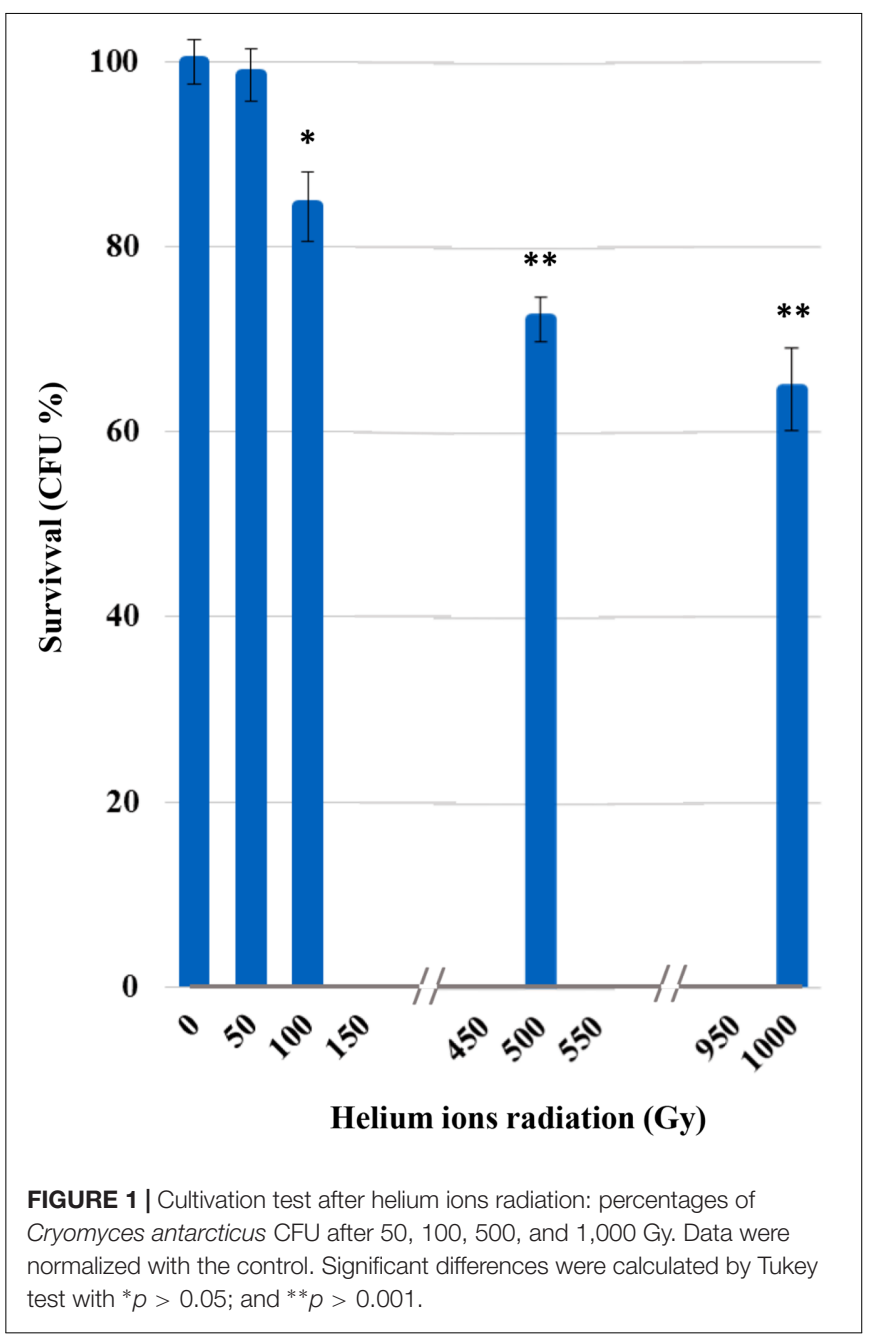




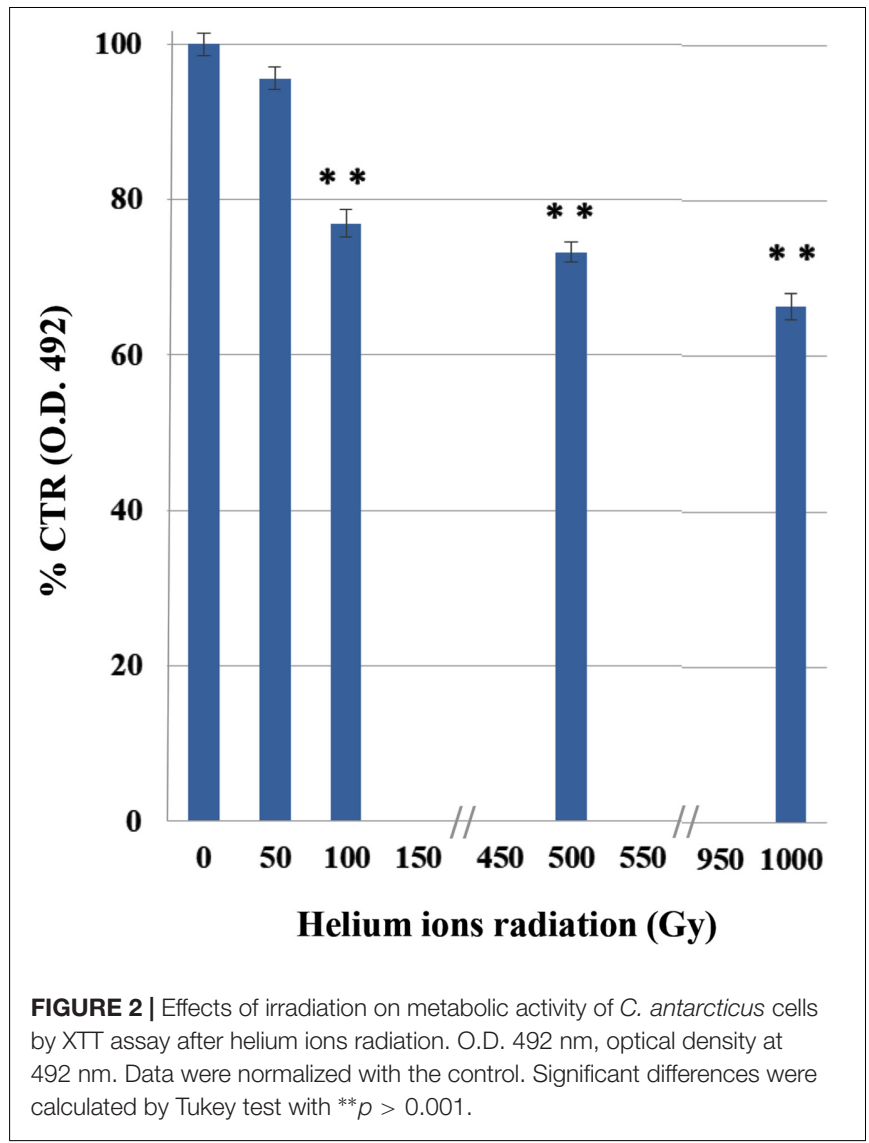

mitochondrial membrane and also an intact cell membrane, do have active dehydrogenase. The first significant reduction was measured at $100 \mathrm{~Gy}(77 \%)$. However, $66 \%$ of metabolic activity compared to the laboratory control is still maintained at the highest doses, confirming the cultivation tests results and showing a good preservation of cell machinery after treatments.

\section{Membrane Damage Assessment}

The integrity of plasma membranes in irradiated cells was assessed by using qPCR after treatments with PMA; this molecule penetrates cells with compromised plasma membranes and inhibit DNA amplification.

This analysis also revealed a progressive damage with the increasing of treatments (Figure 3); no significant damage was present after the lowest treatment (50 Gy) and 68\% damaged cells were recorded at $100 \mathrm{~Gy}$. Besides up to $63 \%$ of cells still maintained membrane integrity after the highest dose (1,000 Gy).

\section{DNA Integrity Assessment}

Amplicons were obtained both for ITS and for ITS-LSU regions, fragments of 700,1,600, and 2,000 bp of C. antarcticus DNA respectively, after irradiation treatments (Figures 4A-C). All bands were well-preserved in 700, 1,600, and 2,000 bp gene length; the gel analyses, performed with ImageJ Software, for all of them measured $100 \%$ relative density of the band till

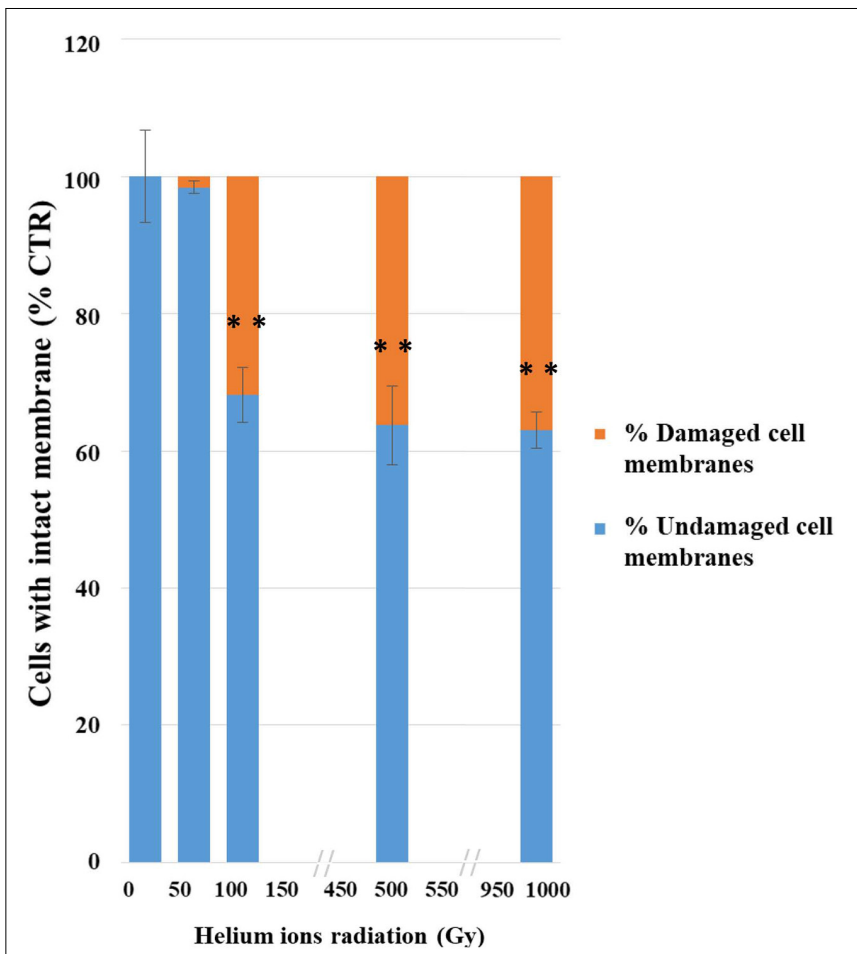

FIGURE 3 | Results of PMA assay coupled with qPCR after helium ions radiation: 50, 100, 500, and 1,000 Gy. The graph shows percentages of C. antarcticus cells with intact membrane, normalized with the control. Percentages of $C$. antarcticus cells with damaged membrane (Red), and corresponding percentages of cells (Blue) with intact membrane. Significant differences were calculated by Tukey test with ${ }^{* *} p>0.001$.

the highest irradiation dose. The RAPD profiles were preserved in all the conditions tested (Figure 4D). A reduction of band intensity in $1 \mathrm{kGy}$ irradiated samples was visible for the band round 1,000 bp while the highest molecular weight (MW) bands were maintained. This is difficult to explain since the highest MW bands (about 2,200 bp) of the RAPD profiles would have disappeared first in case of DNA damage (Atienzar et al., 2002); moreover, in the single gene amplification, band intensity was maintained even for DNA amplicons of 2,000 bp. In the overall, results indicate that these kinds of treatments did not cause any detectable damage to the fungal DNA, at least with the techniques here used; unfortunately, for organisms with such a thick cell wall other procedures, theoretically more appropriate to reveal DNA damage as the comet assay, are not applicable.

The possible mutational burden gained by the fungus after irradiation was studied by amplicon sequencing. The electropherograms appeared perfectly preserved with no single mutation detectable (data not shown).

\section{Ultrastructural Damage Assessment}

Despite the dehydration treatments, control cells were perfectly preserved (Figures 5A,B), with well-organized cytoplasm and cell membrane integrity (Figure 5A, right black arrow). Nucleus and vacuole (Figure 5A, black arrow) were well-visible. 


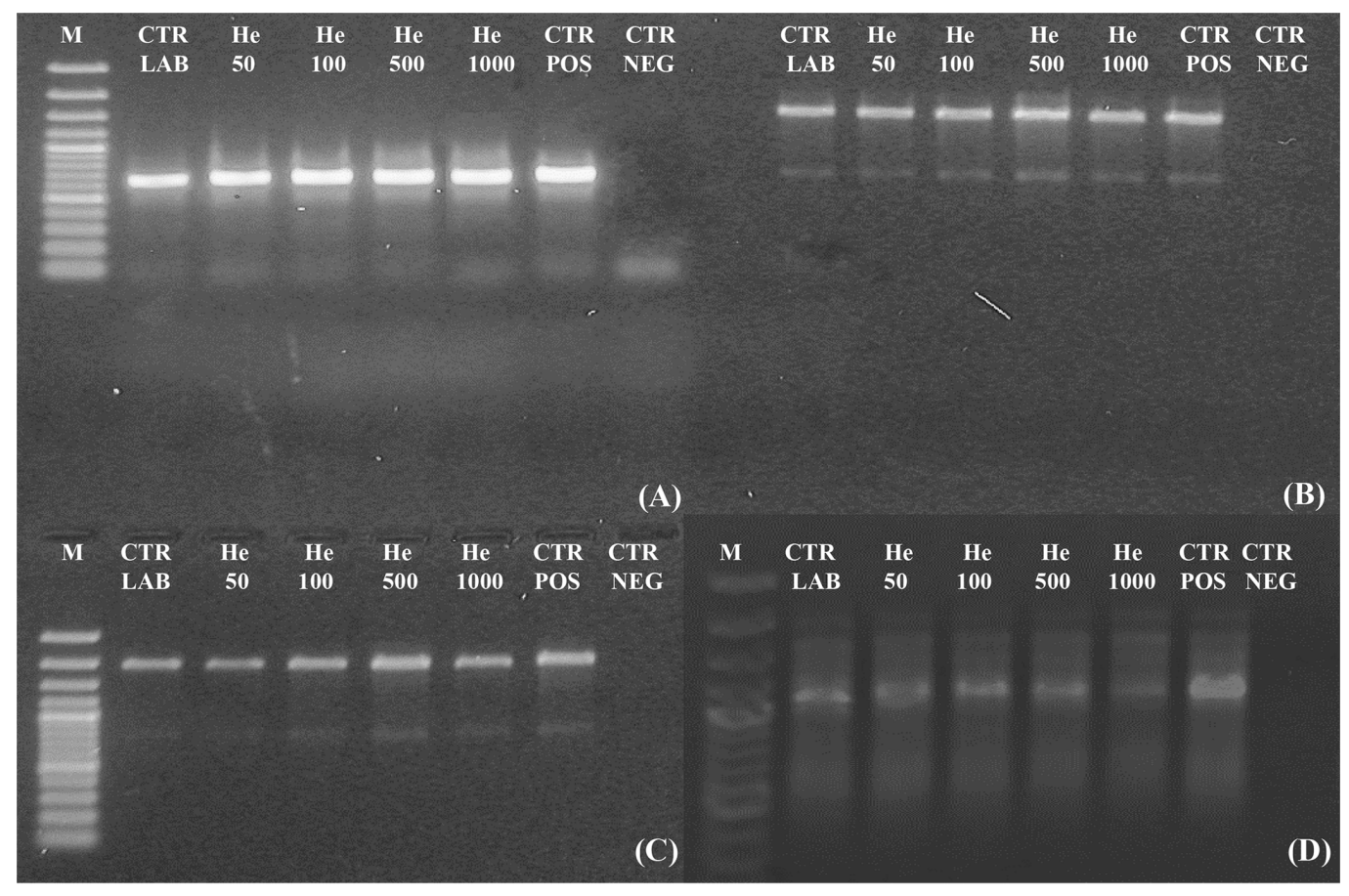

FIGURE 4 | Assessment of the DNA integrity on C. antarcticus single gene PCR (A) 700 bp; (B) 1,600 bp; (C) 2,000 bp and (D) genomic DNA damage as revealed by RAPD assay. M: DNA ladder, POS CTR: fresh colonies, NEG CTR: PCR negative control.

Even samples treated with 500 Gy were rather well-preserved (Figures 5C-F). Cell membranes were always maintained (Figures 5C-F, black arrows) except for cell on the right, Figure 5D, white arrow, where also cytoplasm organization was lost; organelles as nuclei, vacuoles and lipid bodies were also visible in most of the cells (Figures 5C,D, black arrow).

Membrane integrity and cytoplasm organization were maintained also at the highest dose of 1,000 Gy (Figures 5G,H black arrows), while plasmolysis and amorphous cytoplasm are evident in the cell documented in Figure 5G, white arrow. These results support data recorded with cultivation test, proving that a very good vitality was maintained even at the highest dose applied.

\section{DISCUSSION}

Given past and present interest of the Space Agencies in the long-term effects of ionizing radiation on survival, it is surprising that relatively few studies have been addressed to this issue. Helium ions inducing a high-linear energy transfer (LET) are of special interest for their potential biological action. Efforts have been played not only to elucidating fundamental radiobiological mechanisms, but also to applied aspects such as radiation therapy and human exposure to radiation during space flight. In this study we investigated the responses of a eukaryotic model, the fungus $C$. antarcticus, after irradiation with accelerated helium (high-energy particles), as space-relevant radiation. Helium nuclei are densely ionizing radiation sources (high LET radiation) and are of special concern as major source of radiation exposure in outer space (Horneck, 1994). In particular, ions of cosmic radiation are used to set the ultimate limit on (micro-)organisms survival in space (Horneck et al., 1994).

HZE particles (heavy ions) are the biologically most effective component of GCR; doses applied in this experiment are very high even compared to real space, where a putative organism should be exposed over extended periods of time to receive a comparable dose. One kGy of helium radiation corresponds to an average of approximately $2.0 \times 10^{5} \mathrm{He}$ ions (Verseux et al., 2017). As measured during several space missions, for instance during the LDEF mission (Horneck et al., 1994), fluence was very low, around $6 \times 10^{-5}$ particles/year- $\mu \mathrm{m}^{2}$; as a consequence, they would not represent the major danger for a putative microorganism in space (Horneck et al., 2010).

Despite their high potential danger, alpha particles are more easily screened that other harmful radiation as beta or, even more, gamma radiation. The very thick and strongly melanized cell wall of our model organism may have represented an effective barrier for stopping He nuclei, even associated to high LET. In fact, no reduction of survival, metabolic activity or even cell with damaged membrane was detected at $50 \mathrm{~Gy}$. Survival, PMA, and XTT tests gave a progressive reduction at the other irradiation doses. We assume that the first dose was not that high for our test organism to cause appreciable damage. The effect of treatments on the cells was progressively higher, and comparable among different tests, at 100,500, and 1,000 Gy. 

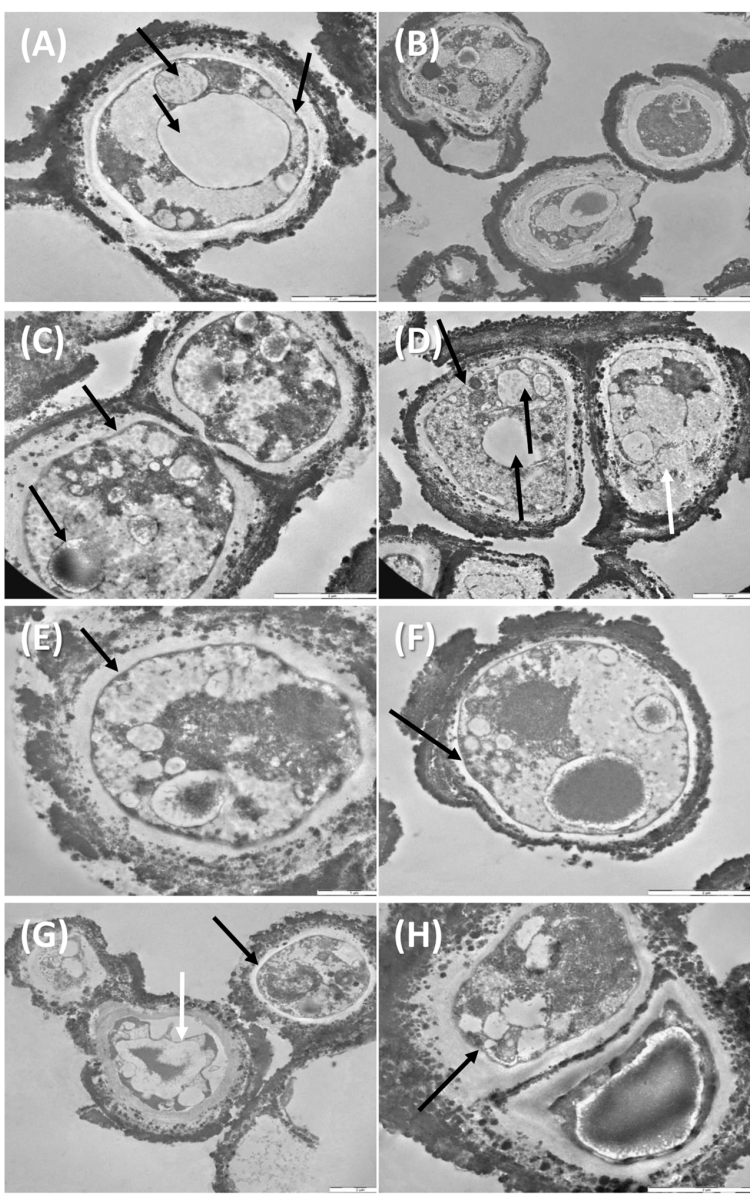

FIGURE 5 | TEM observations of C. antarcticus: Control (A,B); 500 Gy treatments, (C-F) cell membrane and organelles are perfectly preserved (black arrows, C-F), damaged membrane (white arrow, D); 1,000 Gy treatments $(\mathbf{G}, \mathbf{H})$ plasmolysis and amorphous cytoplasm (white arrow, $\mathbf{G}$ ) well-preserved membrane (black arrow, $\mathbf{G}, \mathbf{H}$ ).

This may justify the high survival and metabolic activity observed even at the maximum dose tested in the experiment where still $64 \%$ of living cells and $66 \%$ of metabolic activity were maintained, respectively.

Accordingly, still $63 \%$ of cells with intact membrane were present after PMA-qPCR assay at the highest irradiation dose (1,000 Gy). A general good membrane integrity was also observed with TEM; cell membrane was mostly preserved even at high doses applied while damages were visible in some cells at 1,000 Gy treatment in terms of membrane integrity and cytoplasm preservation (Figure 5). As reviewed by Horneck et al. (1994), DNA double-strand breaks (DSBs) are the most severe type of damage induced by HZE particles in microorganisms, as determined in cells of Escherichia coli, Deinococcus radiodurans, and Bacillus subtilis. Nevertheless, DNA damage was not detectable at all in our model $C$. antarcticus; single gene amplifications were successful even at highest dose and longest gene sequences tested; accordingly, the fingerprinting profiles were perfectly maintained (Figure 4).

These results were consistent with the other STARLIFE models as the cyanobacterium Chroococcidiopsis sp. and the lichen Circinaria gyrosa that also survived the treatment (de la Torre et al., 2017; Verseux et al., 2017). C. antarcticus has been extensively tested for its resistance to the space-relevant radiation (Onofri et al., 2012, 2015; Pacelli et al., 2016, 2017b). However, the tolerance mechanisms of this astrobiological model to outer space environmental stresses are still poorly understood but they could be related to its ability to survive desiccation. In fact, during anhydrobiosis, a state of metabolic inactivity after desiccation (Kranner et al., 2008), radiolysis of intracellular water, that is the most significant source of hazardous reactive oxygen species (Kovács and Keresztes, 2002), does not occur or is almost absent.

This radio-resistance of cells in a dry state was previously observed in bacteria as Deinococcus radiodurans (Bauermeister et al., 2011) and Halobacterium salinarum (Leuko et al., 2015; Leuko and Rettberg, 2017; Verseux et al., 2017) and was also addressed to reduced number of reactive oxygen species, and lower rates of harmful chemical reactions, when cells are in a dry state (Bauermeister et al., 2011).

In our study, the fungal DNA remained perfectly detectable even after exposure to $1 \mathrm{kGy}$ of $\mathrm{He}^{2+}$ ions. These results are consistent with what previously observed when the fungus was treated with gamma-ionizing radiation (Pacelli et al., 2017b) and to other factors encountered in space and under Mars-like conditions (Pacelli et al., 2016). The DNA detectability after radiation treatments was reported for other microorganisms tested in the frame of STARLIFE project (Verseux et al., 2017). Those findings are relevant to search-for life missions on Mars, confirming this molecule as putative biosignature since its presence provides unequivocal proof of present or recently past life even if, it must be taken into account, that extracellular DNA may be bound to minerals or destroyed once hydrated (Aerts et al., 2014; Mojarro et al., 2017). Life detection missions to Mars focus on detecting biomarkers as evidence for extant or extinct life (Parnell et al., 2007; De Vera et al., 2012). The surface of Mars is continuously exposed to high levels of cosmic radiation, which could be deleterious for both microorganisms survival and persistence of molecular biosignatures such as DNA (Dartnell et al., 2007). Being amplified even after helium ions and ionizing radiation (Pacelli et al., 2017b; Verseux et al., 2017), we largely demonstrated that DNA has a high intrinsic stability and that it could be account as biosignature.

Even if space radiation is quite more complex and cannot be fully simulated on Earth, these results may help us to better understand the effects of helium ions radiation in future astrobiological simulation and real exposure experiments on fungal models and eukaryotic cells in general. This approach will more precisely elucidate the effects of space radiation on fungal resistance and aid in developing personalized radiological countermeasures for astronauts in the frame of planetary protection. 


\section{AUTHOR CONTRIBUTIONS}

CP, SO, and LS designed the study. CP, RM, and AF performed the experiment. CP, SO, LS, and LZ analyzed and interpreted the data. $\mathrm{CP}$ wrote a first draft of the manuscript, which was corrected, revised and approved by all authors.

\section{FUNDING}

CP, SO, LS, and LZ were supported by BIOMEX MCF Experiment on ISS for tracking biosignatures on Martian and Lunar rocks analogs and E-GEM GeoMicrobiology for Space Exploration grants. AF and RM - MEXT Grant-in-Aid for Scientific Research on Innovative Areas "Living in Space" (Grant Numbers: 15H05935, 15K21745). RM - was supported by the DLR grant

\section{REFERENCES}

Aerts, J. W., Röling, W. F., Elsaesser, A., and Ehrenfreund, P. (2014). Biota and biomolecules in extreme environments on Earth: implications for life detection on Mars. Life 4, 535-565. doi: 10.3390/life4040535

Atienzar, F. A., Venier, P., Jha, A. N., and Depledge, M. H. (2002). Evaluation of the random amplified polymorphic DNA (RAPD) assay for the detection of DNA damage and mutations. Mutat. Res. 521, 151-163. doi: 10.1016/S1383-5718(02) 00216-4

Bauermeister, A., Moeller, R., Reitz, G., Sommer, S., and Rettberg, P. (2011). Effect of relative humidity on Deinococcus radiodurans' resistance to prolonged desiccation, heat, ionizing, germicidal, and environmentally relevant UV radiation. Microb. Ecol. 61, 715-722. doi: 10.1007/s00248-010-9785-4

Box, G. E., Hunter, W. G., and Hunter, J. S. (1978). Statistics for Experimenters: An Introduction to Design, Data Analysis, and Model Building, Vol. 1. New York, NY: Wiley.

Clark, B. C. (2001). Interplanetary interchange of bioactive material: probability factors and implications. Orig. Life Evol. Biosph. 31, 185-197. doi: 10.1023/A: 1006757011007

Cordero, R. J. (2017). Melanin for space travel radioprotection. Environ. Microbiol. 19, 2529-2532. doi: 10.1111/1462-2920.13753

Dartnell, L. (2011). Biological constraints on habitability. Astron. Geophys. 52, 1.25-1.28. doi: 10.1111/j.1468-4004.2011.52125.x

Dartnell, L. R., Desorgher, L., Ward, J. M., and Coates, A. J. (2007). Martian subsurface ionising radiation: biosignatures and geology. Biogeosciences 4, 455-492. doi: 10.5194/bg-4-545-2007

de la Torre, R., Miller, A. Z., Cubero, B., Martín-Cerezo, M. L., Raguse, M., and Meeßen, J. (2017). The effect of high-dose ionizing radiation on the astrobiological model lichen Circinaria gyrosa. Astrobiology 17, 145-153. doi: 10.1089/ast.2015.1454

De Vera, J. P., Boettger, U., de la Torre Noetzel, R., Sánchez, F. J., Grunow, D., Schmitz, N., et al. (2012). Supporting Mars exploration: BIOMEX in Low Earth Orbit and further astrobiological studies on the Moon using Raman and PanCam technology. Planet. Space Sci. 74, 103-110. doi: 10.1016/j.pss.2012. 06.010

Durante, M., and Cucinotta, F. A. (2011). Physical basis of radiation protection in space travel. Rev. Mod. Phys. 83, 1245-1281. doi: 10.1103/RevModPhys. 83.1245

Goodhead, D. T. (1994). Initial events in the cellular effects of ionizing radiations: clustered damage in DNA. Int. J. Radiat. Biol. 65, 7-17. doi: 10.1080/ 09553009414550021

Goodhead, D. T. (1999). Mechanisms for the biological effectiveness of high-LET radiations. J. Radiat. Res. 40,1-13. doi: 10.1269/jrr.40.S1

Hawrylewicz, E., Gowdy, B., and Ehrlich, R. (1962). Micro-organisms under a simulated Martian environment. Nature 193, 497. doi: 10.1038/193497a0

Horneck, G. (1994). HZE particle effects in space. Acta Astronaut. 32, 749-755. doi: 10.1016/0094-5765(94)90170-8
FuE-Projekt "ISS LIFE” (Programm RF-FuW, Teilprogramm 475).

\section{ACKNOWLEDGMENTS}

We would like to thank to the Italian Space Agency (ASI) for co-funding the research (BIOMEX MCF and E-GEM GeoMicrobiology for Space Exploration grants), the Italian National Program of Antarctic Researches (PNRA) and Italian National Antarctic Museum "Felice Ippolito" for funding the collection of Antarctic samples and preservation of strains in the CCFEE. We also would like to thank the HIMAC facility at the NIRS in Chiba, Japan to perform the irradiation. The authors thank Andrea Schröder for her technical assistance during parts of this work.

Horneck, G., Bücker, H., and Reitz, G. (1994). Long-term survival of bacterial spores in space. Adv. Space Res. 14, 41-45. doi: 10.1016/0273-1177(94)90448-0

Horneck, G., Klaus, D. M., and Mancinelli, R. L. (2010). Space microbiology. Microbiol. Mol. Biol. Rev. 74, 121-156. doi: 10.1128/MMBR.00016-09

Kong, L., Dong, J., and Hart, G. E. (2000). Characteristics, linkage-map positions, and allelic differentiation of Sorghum bicolor (L.) Moench DNA simplesequence repeats (SSRs). Theor. Appl. Genet. 101, 438-448. doi: 10.1007/ s001220051501

Kovács, E., and Keresztes, A. (2002). Effect of gamma and UV-B/C radiation on plant cells. Micron 33, 199-210. doi: 10.1016/S0968-4328(01)00012-9

Kranner, I., Beckett, R., Hochman, A., and Nash, T. H. III (2008). Desiccationtolerance in lichens: a review. Bryologist 111, 576-593. doi: 10.1639/0007-2745111.4.576

Kuhn, D. M., Balkis, M., Chandra, J., Mukherjee, P. K., and Ghannoum, M. A. (2003). Uses and limitations of the XTT assay in studies of Candida growth and metabolism. J. Clin. Microbiol. 41, 506-508. doi: 10.1128/JCM.41.1.506508.2003

Leuko, S., Domingos, C., Parpart, A., Reitz, G., and Rettberg, P. (2015). The survival and resistance of Halobacterium salinarum NRC-1, Halococcus hamelinensis, and Halococcus morrhuae to simulated outer space solar radiation. Astrobiology 15, 987-997. doi: 10.1089/ast.2015.1310

Leuko, S., and Rettberg, P. (2017). The effects of HZE particles, $\gamma$ and X-ray radiation on the survival and genetic integrity of Halobacterium salinarum NRC-1, Halococcus hamelinensis, and Halococcus morrhuae. Astrobiology 17, 110-117. doi: 10.1089/ast.2015.1458

Mileikowsky, C., Cucinotta, F. A., Wilson, J. W., Gladman, B., Horneck, G., Lindegren, L., et al. (2000). Natural transfer of viable microbes in space, part 1: from Mars to Earth and Earth to Mars. Icarus 145, 391-427. doi: 10.1006/ icar.1999.6317

Moeller, R., Raguse, M., Leuko, S., Berger, T., Hellweg, C. E., Fujimori, et al. (2017). STARLIFE - an international campaign to study the role of galactic cosmic radiation in astrobiological model systems. Astrobiology 17, 101-109. doi: $10.1089 /$ ast.2016.1571

Mojarro, A., Ruvkun, G., Zuber, M. T., and Carr, C. E. (2017). Nucleic acid extraction from synthetic mars analog soils for in situ life detection. Astrobiology 17, 747-760. doi: 10.1089/ast.2016.1535

Nicholson, W. L. (2009). Ancient micronauts: interplanetary transport of microbes by cosmic impacts. Trends Microbiol. 17, 243-250. doi: 10.1016/j.tim.2009. 03.004

Nicholson, W. L., Schuerger, A. C., and Race, M. S. (2009). Migrating microbes and planetary protection. Trends Microbiol. 17, 389-392. doi: 10.1016/j.tim.2009. 07.001

Onofri, S., de la Torre, R., de Vera, J. P., Ott, S., Zucconi, L., Selbmann, L., et al. (2012). Survival of rock-colonizing organisms after 1.5 years in outer space. Astrobiology 12, 508-516. doi: 10.1089/ast.2011.0736

Onofri, S., de Vera, J. P., Zucconi, L., Selbmann, L., Scalzi, G., Venkateswaran, K. J., et al. (2015). Survival of antarctic cryptoendolithic fungi in simulated martian 
conditions on board the international space station. Astrobiology 15, 1052-1059. doi: 10.1089/ast.2015.1324

Pacelli, C., Bryan, R. A., Onofri, S., Selbmann, L., Shuryak, I., and Dadachova, E. (2017a). Melanin is effective in protecting fast and slow growing fungi from various types of ionizing radiation. Environ. Microbiol. 19, 1612-1624. doi: 10.1111/1462-2920.13681

Pacelli, C., Selbmann, L., Zucconi, L., de Vera, J. P., Rabbow, E., Horneck, G., et al. (2016). BIOMEX experiment: ultrastructural alterations, molecular damage and survival of the fungus Cryomyces antarcticus after the Experiment Verification Tests. Orig. life. Evol. Biosph. 47, 187-202. doi: 10.1007/s11084-016-9485-2

Pacelli, C., Selbmann, L., Zucconi, L., Raguse, M., Moeller, R., Shuryak, I., et al. (2017b). Survival, DNA integrity, and ultrastructural damage in Antarctic cryptoendolithic eukaryotic microorganisms exposed to ionizing radiation. Astrobiology 17, 126-135. doi: 10.1089/ast.2015.1456

Parnell, J., Cullen, D., Sims, M. R., Bowden, S., Cockell, C. S., Court, R., et al. (2007). Searching for life on Mars: selection of molecular targets for ESA's aurora ExoMars mission. Astrobiology 7, 578-604. doi: 10.1089/ast.2006.0110

Rabbow, E., Rettberg, P., Barczyk, S., Bohmeier, M., Parpart, A., Panitz, C., et al. (2012). EXPOSE-E: an ESA astrobiology mission 1.5 years in space. Astrobiology 12, 374-386. doi: 10.1089/ast.2011.0760

Rabbow, E., Rettberg, P., Barczyk, S., Bohmeier, M., Parpart, A., Panitz, C., et al. (2015). The astrobiological mission EXPOSE-R on board of the International Space Station. Int. J. Astrobiol. 14, 3-16. doi: 10.3389/fmicb.2017.01533

Rummel, J. D. (2001). Planetary exploration in the time of astrobiology: protecting against biological contamination. Proc. Natl. Acad. Sci. U.S.A. 98, 2128-2131. doi: 10.1073/pnas.061021398

Schneider, C. A., Rasband, W. S., and Eliceiri, K. W. (2012). NIH Image to ImageJ: 25 years of image analysis. Nat. Methods 9, 671-675. doi: 10.1038/nmeth.2089

Selbmann, L., de Hoog, G. S., Mazzaglia, A., Friedmann, E. I., and Onofri, S. (2005). Fungi at the edge of life: cryptoendolithic black fungi from Antarctic desert. Stud. Mycol. 51, 1-32.

Selbmann, L., Isola, D., Egidi, E., Zucconi, L., Gueidan, C., de Hoog, G. S., et al. (2014). Mountain tips as reservoirs for new rock-fungal entities: Saxomyces gen. nov. and four new species from the Alps. Fungal Divers. 65, 167-182 doi: 10.1007/s13225-013-0234-9

Selbmann, L., Isola, D., Zucconi, L., and Onofri, S. (2011). Resistance to UV-B induced DNA damage in extreme-tolerant cryptoendolithic Antarctic fungi: detection by PCR assays. Fungal Biol. 115, 937-944. doi: 10.1016/j.funbio.2011. 02.016

Sutherland, B. M., Bennett, P. V., Sidorkina, O., and Laval, J. (2000). Clustered damages and total lesions induced in DNA by ionizing radiation: oxidized bases and strand breaks. Biochemistry 39, 8026-8031. doi: 10.1021/bi99 27989

Verseux, C., Baqué, M., Cifariello, R., Fagliarone, C., Raguse, M., Moeller, R., et al. (2017). Evaluation of the resistance of Chroococcidiopsis spp. to sparsely and densely ionizing irradiation. Astrobiology 17, 118-125. doi: 10.1089/ast.2015. 1450

Vilgalys, R., and Hester, M. (1990). Rapid genetic identification and mapping of enzymatically amplified ribosomal DNA from several Cryptococcus species. J. Bacteriol. 172, 4238-4246. doi: 10.1128/jb.172.8.4238-4246.1990

White, T. J., Bruns, T., Lee, S., and Taylor, J. (1990). “Amplification and direct sequencing of fungal ribosomal RNA genes for phylogenetics," in PCR Protocols: A Guide to Methods and Applications, eds N. Innis, D. Gelfand, J. Sninsky, and T. White (Cambridge, MA: Academic Press), 315-322.

Conflict of Interest Statement: The authors declare that the research was conducted in the absence of any commercial or financial relationships that could be construed as a potential conflict of interest.

Copyright (c) 2017 Pacelli, Selbmann, Moeller, Zucconi, Fujimori and Onofri. This is an open-access article distributed under the terms of the Creative Commons Attribution License (CC BY). The use, distribution or reproduction in other forums is permitted, provided the original author(s) or licensor are credited and that the original publication in this journal is cited, in accordance with accepted academic practice. No use, distribution or reproduction is permitted which does not comply with these terms. 